\title{
Exploring Ethical Validation as a Key Consideration in Interpretive Research Quality
}

\section{Dr. Joachim Walther, University of Georgia}

Dr. Walther is an assistant professor of engineering education research at the University of Georgia (UGA). He is a director of the Collaborative Lounge for Understanding Society and Technology through Educational Research (CLUSTER), an interdisciplinary research group with members from engineering, art, educational psychology and social work.

His research interests range from the role of empathy in engineering students' professional formation, the role of reflection in engineering learning, and interpretive research methodologies in the emerging field of engineering education research.

His teaching focuses on innovative approaches to introducing systems thinking and creativity into the environmental engineering program at the University of Georgia.

\section{Dr. Alice L. Pawley, Purdue University, West Lafayette}

Alice Pawley is an Associate Professor in the School of Engineering Education and an affiliate faculty member in the Gender, Women's and Sexuality Studies Program and the Division of Environmental and Ecological Engineering at Purdue University. She was co-PI of Purdue's ADVANCE program from 2008-2014, focusing on the underrepresentation of women in STEM faculty positions. She runs the Feminist Research in Engineering Education (FREE, formerly RIFE, group), whose diverse projects and group members are described at feministengineering.org. She received a CAREER award in 2010 and a PECASE award in 2012 for her project researching the stories of undergraduate engineering women and men of color and white women. She received ASEE-ERM's best paper award for her CAREER research, and the Denice Denton Emerging Leader award from the Anita Borg Institute, both in 2013. She helped found, fund, and grow the PEER Collaborative, a peer mentoring group of early career and recently tenured faculty and research staff primarily evaluated based on their engineering education research productivity. She can be contacted by email at apawley@ purdue.edu.

\section{Dr. Nicki Wendy Sochacka, University of Georgia}

Dr. Nicki Sochacka received her doctorate in Engineering Epistemologies from the University of Queensland, Australia, in 2011. She is currently a member of the CLUSTER research group at the University of Georgia where she holds a research and teaching position. Nicki's areas of research interest include: STEAM (STEM + Art) education, diversity, interpretive research quality, the role of empathy in engineering education and practice, and student reflection. 


\title{
Exploring ethical validation as a key consideration in interpretive research quality
}

\begin{abstract}
The engineering education community is adopting an increasingly diverse range of qualitative methods. This rapid expansion in required methodological expertise has sparked a vibrant discourse around ways to foster and articulate research quality in qualitative and mixed-methods studies. This paper describes three engineering education scholars' engagement with a processoriented framework for interpretive research quality. Set in the context of a collaborative inquirybased approach to reflecting on and improving research practice, this paper presents five instances when we turned to the framework to address quality challenges that emerged in our own research projects. Analysis of these experiences demonstrates the exploratory and explanatory power of the existing framework. At the same time, however, our collaborative process revealed the need to consider another dimension of research quality, specifically concerned with the human experience of the researcher and the researched throughout the inquiry. In this context, we propose Ethical Validation as a validation construct that, we argue, lies at the heart of conducting and evaluating interpretive research.
\end{abstract}

\section{Introduction}

As the field of engineering education research embraces an ever broader range of interpretive methods of inquiry, engineering education scholars are searching for ways to coherently conceptualize and integrate research quality considerations in qualitative and mixed-methods projects and convey the trustworthiness and value of this type of work to others.

In this paper we build on a prior parsimonious framework for interpretive research quality that was recently developed by Walther et al. ${ }^{1}$. This framework, which is described in more detail in the Theoretical Framework section below, offers a process view on research quality that spans the entire research project (represented as the two phases of Making Data and Handling Data) and proposes six quality constructs (Theoretical, Procedural, Communicative, and Pragmatic Validation and Process Reliability) to facilitate the exploration of quality issues and the application of quality strategies across a wide range of methodologies.

Based on our use of the Quality Framework in our ongoing research projects, this paper provides an expanded, practice-based sense of its application through a number of practice anecdotes that are analyzed through the constructs of the framework. These explorations draw on research practice from two interpretive studies conducted by the authors ${ }^{2-4}$. In this paper we draw our respective research documentation (i.e., log trails etc.) in combination with a collaborative inquiry approach to analyze and discuss key challenges around research quality that surfaced in each of the two projects.

These analyses reveal that while the Quality Framework provides a language to identify, articulate, and navigate key issues of research quality from a theoretical perspective, the framework did not (and could not) capture the full extent of our experiences in navigating those challenges. In particular, we noticed that a range of deep ethical considerations and the aspect of both researchers' and participants' emotions in the process seemed to fundamentally underpin 
the quality considerations but were not reflected in the theoretical examinations using the existing five quality constructs in the framework.

Based on the collaborative exploration of these experiences, we develop the notion of "Ethical Validation" as a new, key component in considerations of interpretive research quality. We propose that this new, sixth construct spans the entire research process, from Making to Handling data, and intersects with and integrates the prior quality constructs to complement the contextually holistic view on research quality proposed in the original framework.

\section{Literature review}

Due to their significance for research funding, institutional practices around human subject reviews often dominate ethical considerations of qualitative research ${ }^{5,6}$. Such considerations are predominantly concerned with compliance to the principles and policies established by Institutional Review Boards (IRBs) that implement federal regulations ${ }^{7}$ and inherently emphasize early phases of research design.

The guiding principles of IRBs are historically and intellectually rooted in the utilitarian ethics of value free social sciences ${ }^{8}$. This epistemology presumes the possibility of objective, rational choices with respect to research ethics by: (i) safeguarding the rights and freedom of autonomous individuals, and (ii) balancing the risks of research with external benefits ${ }^{5}$. These principles are embodied in IRB procedures through stipulations around informed consent, privacy and confidentiality, and an assessment of risk to participants that is balanced against the benefits of the research. This view of the role of ethics in social research where "ethical ends [are] external to scientific means" ${ }^{\prime \prime}$ is at heart a research quality consideration in the positivist paradigm. For example, Christians ${ }^{8}$ observed that "the exteriority of ethics is seen to guarantee the value neutrality of experimental procedures" (p. 144). The qualitative research community has criticized these practices as not appropriate for the epistemological tenets of qualitative research and has offered a range of other frameworks through which to consider questions of research ethics.

Feminist research communities, for example, have long struggled with the scientific edict to "stay objective", "disconnected", and "dispassionate" about one's research endeavors both from a moral and a research quality standpoint. Regarding the latter, Donna Haraway ${ }^{9}$ noted the impossibility of leaving aside one's political or moral commitments, social location, and interests, about what she described as the impossibility of "the god trick of seeing everything from nowhere" (p. 581). Sandra Harding ${ }^{10}$ picked up on this idea, and argued that trying to remain objective in doing sciences was in fact to do disservice to science itself. She offered the idea of a "strong objectivity," arguing that:

Cultural agendas and assumptions are part of the background assumptions and auxiliary hypotheses that philosophers have identified. If the goal [of scientific research] is to make available for critical scrutiny all the evidence marshaled for or against a scientific hypothesis, then this evidence too requires critical examination within scientific research processes. In other words, we can think of strong objectivity as extending the notion of 
scientific research to include systematic examination of such powerful background beliefs. It must do so in order to be competent at maximizing objectivity. (p. 149)

Here, Harding is claiming that this is a "strong" objectivity in contrast to the usual scientific "weak" objectivity of striving to leave aside all of one's social understandings of the world; indeed, one's own social location and perspectives are part of the data for understanding some social reality, and to ignore them is to incompletely analyze the social reality of interest. So to incorporate a sensitivity to one's own moral, ethical, and political commitments and standpoints is to do research of a higher quality than to try to cast them aside.

Mia Ong brought this discussion into her reflections on a "methodological activism," where she joins others to "promote methods and the discussion of methods as an activist's way of enacting social change" (p. 3). She noted, as have others, how methodological choices in research can reflect a certain politics and risk reproducing various power relationships that the researcher may be hoping to problematize. Through describing three methodological dilemmas, she notes how she is trying to perform a different kind of research, not just because of a commitment to feminist epistemological or methodological principles but because it also helps her better understand the social reality she is investigating. She describes how she "got involved" with her participants in a longitudinal study, becoming a friend and a confidante over the years, and as a result, her participants shared more than they would have in a 1-instance interaction, letting her better understand the experiences of minority people in physics. She talked about using "care as intervention" - that through her long-time interaction for research purposes, her participants came to see her as a stakeholder in their lives connected to physics, and a reason to continue to pursue it. Finally, she discusses how she shared her findings with her participants, and through these conversations:

[...] they have gained a more sophisticated vocabulary, discourse, and frame of analysis to understand and talk about their own experiences. They have used this knowledge for their own enrichment, or at least to help normalize their own experiences, to educate others around them such as partners, faculty, and peers, and to become potentially active themselves. (p. 11)

So by engaging in ways she determined as more ethically aligned with her research philosophy than the standard "objectivity," Ong was able to theorize her participants' experiences more deeply and with more sure-footedness, come to better understand the social reality under investigation.

By this point, we have described how ethics has been treated through micro IRB processes, and we have referenced the conversation in feminist theory about how ethics and quality interact. Expanding the analysis of prior literature around the relationship between ethics and research quality, we connect with the conversation around decolonizing methodologies, which are various methodologies and methods through which researchers strive to resist colonial appropriation of cultural or community knowledge that benefits their own careers but has arguably little contribution to the community itself. A leader in this area, Linda Tuhiwai Smith ${ }^{12}$ outlines a comprehensive overhaul of the practice of "normal research" by putting at its heart care and commitment for indigenous communities. She articulates "an indigenous research agenda" 
focused around conducting community research, tribal research, and "Insider/Outsider" research, which talks not just about the subject of study and the methods by which researchers approach the study, but how making just choices in our collective designs has the potential to subvert historical research practices that have their roots in colonialism. For Tuhiwai Smith and others in this movement, justice is at the heart of their research endeavors in order to counter hegemonic colonial narratives about indigenous and subordinated people. So, put plainly, to do otherwise is to ignore decades of critical research decrying the flaws of research done with a colonial backdrop.

This brief overview of the literature illustrates the potential limitations of traditional approaches to research ethics when applied to qualitative research, a challenge that is crucially important for the growing discourse around the use of interpretive methods in engineering education. The analysis of prior work in the areas of feminist and de-colonizing methodologies points to the inherent link between considering ethics as an integral part of research and the holistic quality of research findings. In the following we build on this discussion to explore a practice-based way of integrating ethical considerations into the research process as part of a larger, cohesive consideration of research quality.

\section{Theoretical framework}

The Quality Framework that provides the theoretical basis for our analysis of the research practice anecdotes below consists of: (i) a process model of the inquiry, and (ii) a typology of validation constructs.

\section{(i) Process model of research quality}

As described in Walther et al. ${ }^{1}$, the process model of research quality shifts the focus from assessing the quality of research end-products to infusing and demonstrating research quality throughout the inquiry to substantiate claims to overall quality or trustworthiness. The model comprises the two broad phases of Making Data and Handling Data that emphasize the interlocking acts of socially constructing meaning in different communication communities ${ }^{13}$ throughout the research project. Making Data entails the early conception of the research project and focuses on how researchers and participants construct a shared understanding of the latter's "experience-near constructs" 14 , that is, the participants' accounts of their social reality in their own terms. Handling Data shifts the focus of meaning making to the research team with the goal of developing the "experience-distant constructs", that is, the knowledge claims or contributions to theory that are grounded in participants' lived realities but are constructed within the meaning conventions of the relevant research community.

\section{(ii) Typology of validation constructs}

The typology comprises five validation constructs that conceptualize fundamental aspects or processes that constitute overall quality. These constructs are offered as a parsimonious way to explore issues of research quality across a range of interpretive approaches and to articulate how specific quality strategies or practices contribute to overall quality in the context of a particular inquiry. The validation constructs are listed and briefly described below. Further details concerning these constructs are provided in the relevant analyses of the practice anecdotes and can also be found in ${ }^{1}$. 
- Theoretical Validation concerns the fit between the social reality under investigation and the theory generated.

- Procedural Validation concerns features of the research design that inherently improve the fit between the reality studied and the theory generated.

- Communicative Validation concerns the integrity of the interlocking processes of social construction with the relevant communication communities.

- Pragmatic Validation concerns the compatibility of theoretical constructs with empirical reality.

- Process Reliability concerns the mitigation of random influences on the research process.

\section{Methodology and approach}

\section{Collaborative inquiry}

This work is methodologically and theoretically grounded in the tradition of collaborative inquiry $^{15-19}$, an approach that "provides a systematic structure for learning from experience" 17. In its systematic focus on generating knowledge in the context of efforts to improve practice, this approach is related to action research and action science ${ }^{15,20}$. In contrast to action research, which focuses on improving the social realities of others, collaborative inquiry generates knowledge in the context of purposefully and systematically improving a group's own shared practice. The methods of shared exploration and meaning making in the context of action closely link collaborative inquiry to the principles of adult learning ${ }^{20,21}$.

Applying collaborative inquiry to qualitative engineering education research also offers a possible answer to emerging calls in the broader educational research community to systematically examine our own practice with a view to purposefully advancing our understanding of qualitative research approaches based on evidence and concrete experience ${ }^{22,23}$.

The specific methodology of collaborative inquiry is characterized by the following elements. Researchers:

- engage in "cycles of reflection and action""17;

- "examine data from their own experience" (p. 5);

- sustain "authentic collaboration" to "build meaning through consensual validity testing"21 a concept that closely mirrors the notion of Communicative Validation used in this paper; and

- "practice validity procedures" (p. 8) that evaluate the quality of knowledge claims through impact, value and resonance in one's own practice, a notion that aligns with Pragmatic Validation in the quality framework used here.

\section{Our sustained collaborative approach}

The collaboration on which this paper is based emerged from conversations during a workshop around the initial research quality framework ${ }^{24}$ where the issue that we later termed Ethical Validation lingered on the peripheries of the minds of a small group of participants. Our decision to explore this notion further thus responded to a "sense of personal disquiet"17, in that we felt that a significant aspect of our experience of doing qualitative research was missing from our 
discussions of our practices, a sense of absence or doubt that is reflected in each of the research anecdotes analyzed below.

Based on this shared and acute but at the same time vague and ill-defined interest, we met as a group once or twice a month to discuss methodological challenges we were grappling with in our ongoing research projects. Various ways of recording those experiences and reflections, for example using personal log trails or notes from shared discussions, formed the data for the inquiry presented here. The shared examination of these experiences led to gradual insight that, in turn, infused our respective ways of taking our work beyond those challenges. Emerging across these repeated, iterative, and gradual reflection-action cycles, was the coherent notion of Ethical Validation, which we formulate and illustrate in this article.

\section{Analysis}

In this section, we provide details of the example studies that formed the context of our shared exploration and situate the subsequent practice anecdotes. While drawing on two research projects, the presentation and analysis of the practice anecdotes is ordered here to provide a coherent trajectory from Making to Handling Data and thus organize the shared sense-making we collectively engaged in along the process model of the Quality Framework (see also Figure $1)$.

\section{Context: Example projects}

The first, third, and fifth practice anecdotes are drawn from Alice's NSF CAREER grant. In this project Alice and her research team are using stories of underrepresented engineering students to understand how engineering education institutions are gendered and raced through their

structure. Her theoretical framework is based on Dorothy Smith's work on ruling relations ${ }^{25-27}$, which are the 'operating procedures' by which we collectively coordinate social relations in

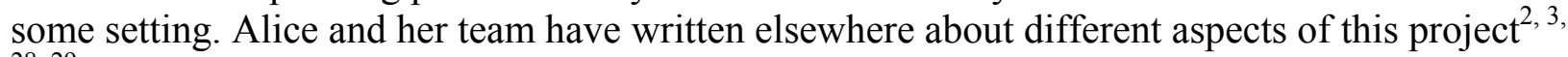
28,29 .

The second and fourth anecdotes are drawn from a project that Nicki and Jo have been working on the past two years. In this project Nicki and Jo are examining stories about engineering that emerge across the collective public discourse and possible implications of these stories for attracting under- and less-represented groups to the profession. The part of the study discussed in this paper is theoretically anchored in the concept of framing from the field of media studies, which highlights the role the media plays in privileging some aspects of a perceived reality over others $^{30}$. Methodologically, the study is informed by the work of Emery Roe ${ }^{31}$ in the field of applied narrative analysis. Nicki, Jo, and their research team have also written elsewhere about different aspects of their project ${ }^{4,28,32}$.

\section{Practice anecdotes: From making to handling data}

The following presents a series of practice anecdotes that span quality considerations along the entire research process from making to handling data. More specifically, anecdote 1 explores the early conception and planning of a qualitative study, anecdotes 2,3 , and 4 examine the progression of interpretive sense-making in the analysis stage and, finally, anecdote 5 deliberates 
the later stages of handling data in term of finding adequate representations of interpretive findings.

The sections are structured in the following manner. Each practice anecdote begins by providing an authentically rich account of our lived research experience as related to a specific issue or challenge of research quality. Next, reflecting the first stage of our shared sense-making, we analyze the quality issue through one or several relevant dimensions of the Quality Framework. Finally, we describe how our deep engagement with the challenges, actions, doubts, emotions, and reflections we experienced and shared ultimately pointed us to a 'missing piece', that is a methodologically relevant human aspect of conducting the research. In the findings section we draw these 'missing pieces' together into a coherent notion of Ethical Validation as it emerged from our respective research practices and the collaborative inquiry around research quality.

\section{The constructs and motives we bring to the study (Alice)}

I learned about Dorothy Smith's work on ruling relations as a graduate student, and had explored it a bit through my ADVANCE-related research with respect to faculty work ${ }^{33,34-36}$. Ruling relations are conceived of the "operating procedures" by which we coordinate our social relations in organizations - so, for example, how do medical professionals, patients, administrators, government officials, politicians, and insurance companies come together through written documents and in person to coordinate a system like healthcare in the US? In the faculty context, how do faculty members, students, administrators, government funders, and others come together through documentation and in person to coordinate, for example, tenure practices? I was interested in extending this to engineering student life - how did ruling relations influence the structure of undergraduate education? And did it influence engineering differently than the other "letters" of STEM? So I built this theory into my CAREER grant proposal, titled Learning from Small Numbers (LfSN). I grounded my argument in both engineering education research and women's studies literature, and argued that:

1. the choice of much existing engineering education research on gender and race to treat gender and race as independent constructs was problematic from a theoretical perspective and that they should be treated together, or intersectionally ${ }^{37}$; and

2. the focus of much gender and race research in engineering education still focused on how the underrepresented group (here, students) were deficient from the perspective of the existing system - solutions rarely incorporated system-level changes that focused on the biases in the system. I felt that ruling relations provided a theoretical framework to counter this.

In preparing other parts of the proposal, I found I was becoming dissatisfied with using semistructured interview protocols to solicit participants' stories of their experiences of whatever context was under study. I wondered what would happen if I, as the convener of the research study, gave participants freedom to tell me the story of their experience however they wanted to, whether what they chose to include more on their own would help my team and me see a more authentic representation of their educational experiences, one initially less colored, as it were, by my experiences and expectations as a white person of education. So I proposed an open protocol, prompted by the initial question "How did you get to be where you are?", and used ruling 
relations as a frame for follow-up questions. (I have written more about the theoretical constructs involved in the study; please see Pawley ${ }^{2}$.)

The proposal reviewed well, and NSF decided to fund it. I was extraordinarily excited, although also overwhelmed about actually sitting down to do the work proposed. As I started to reflect on the data I had started to collect and start my analysis, however, I began to suspect that I may have inadvertently built in circular logic to my research design. I had come to see much more intensely that the interviews were co-constructions between the participant and me as the researcher conducting the interviews; this was not a novel insight but I understood it more viscerally than before. But through the analysis of these co-constructed interviews, I became concerned that incorporating ruling relations into my theoretical framework, data collection, and analytical process had in fact set me up to necessarily find how ruling relations were important in structuring engineering undergraduate students' experiences of education. It was perhaps a forgone conclusion: I had used a lens of ruling relations at every step along the way, aligned all my research design and operationalization choices with this theoretical frame, so was I not therefore guaranteed to see that ruling relations mattered?

One of the first interviews I conducted was with Moises. Moises was an undergraduate student I met at the NSBE conference, and he was an engaging interviewee right from the start - there was no need to prod him to elaborate on any of his answers, as they were bright and vivid, full of detail. We progressed through his early educational experiences and start of college; and then we hit junior year.

Moises told a story of how he was so exhausted from his coursework that he fell asleep driving his partner through the mountains. He told how his car, which usually pulled right that night pulled left and ran into the side of the mountain rather than go over the cliff. In tears, he expressed his shock and fear, that all his work, his whole life could have been over at that point, in just a brief moment.

I was shaken by this interview, both during and afterwards. Although my notes make no remark of it, I remember during the interview feeling this was a critical moment, a pivot point in Moises's university experience, a precious story that Moises was giving me. What was I going to do to respect that gift? I remember being terribly conscious of how I was performing as a listener to the story - should I offer tissues? Should I give him some time to compose himself, a break to get a drink of water or run to the bathroom? At the same time, my mind was processing furiously - that this part of the story, elicited by my prompting question, caused so much emotion on the part of the participant, did that mean it was particularly relevant, or resonated with him? How, then, did this fit into the ruling relations framework? And, while simultaneously having great empathy and concern for his distress, how could I build on it to explore the relationship further? Or would that be pushing too far down an uncomfortable path, and I should just let it be?

The ways I had learned to do research did not prepare me to understand what to do with my conviction that I had heard something important and that it needed to be treated sensitively both in the rest of the interview and in its analysis. Even though I had learned feminist critiques to the predominant value in engineering of objectivity, I had a hard time finding a way to value what I was convinced was a form of important data: my emotional response to Moises's story. 
Through the process of discussing this project with Jo and Nicki, I have come to think that the idea of Theoretical Validation and of Pragmatic Validation can help me make sense of these experiences. It actually was not preordained that aligning all my research design choices to the theoretical frame would actually work; that is, I could have found that students talked about things that would have not made sense within the frame of ruling relations and intersectionality. The fact that they all did make sense was evidence of their applicability to the situation. The empirical reality was that, through the method of interviewing that I had selected and the theoretical constructs of ruling relations that I had been incorporating into my performance of the interview, Moises and I had developed enough of a connection that, despite the vulnerable nature of his story, he felt it necessary to share it. Should the initial assumptions about the suitability of an open interview protocol have been ill-posed, or should the follow-up questions grounded by the ruling relations framework not have been a "fit," the interview would not have flowed, would not have encouraged Moises (a Black man, sharing such a story with a White (and at the time, pregnant) woman, a stranger) to make himself as vulnerable as he had. In other words, the theory of ruling relations would not have withstood exposure to the social reality of either Moises's undergraduate experience, or the experience of the interview. The theoretical frame allowed us to make sense of the social reality under investigation - all the design choices worked together, "fit," to produce an outcome that helped us understand more about participants' experiences than we did before. This reflected the idea of Theoretical Validation. However, we could also consider the fact that all this "worked" as evidence of "whether these assumptions "survive' the exposure to the social reality in the field", which linked the experience to Pragmatic Validation. So the game wasn't rigged; to the contrary, that it all actually worked together was evidence of the validity of the approach.

However, through the process of our collaborative inquiry, we started to articulate a missing component. In the case of Moises and with others, I found the interviews draining to conduct. After several such emotionally-wrought interviews at the same conference, I found I was feeling a profound awareness of white privilege. As a class-privileged white woman, I was coming to a conference for Black engineers and asking them to share their stories of their education with me, many of which, because of my awareness of the literature on race and U.S. education, I expected to be somewhat fraught, to say the least. What right did I as a white woman have to come to a celebratory and ostensibly safe - from most white people! - community space and ask Black students to bare their hearts and souls to me? In fact, I came to think that I didn't have any "right," and these stories challenged me to reflect on my initial plans as arrogant, of reflecting white privilege. In the face of these thoughts, I rationalized to myself that it was a step taken in solidarity, that my theoretical knowledge of race and gender in engineering education made me a safe ally, and that I would build this commitment into doing high quality research that would "make a difference" on behalf of undergraduate engineering students of color. However, my better realization of how my white privilege was influencing my participation in my own study was not just about "doing right" by my participants, but also was something I needed to be critically aware of in my analysis. How did white privilege influence the questions I had asked in the interview? How did white privilege cast a particular lens over my analytical eye? And how did my interpretations influenced by my white privilege help us think more carefully about ruling relations? In other words, how did white privilege constitute a form of ruling relation both in the content of the interviews and in the practice of analyzing them? 
It was through this realization that Jo, Nicki and I started to see the contours of Ethical Validation. These experiences help us illustrate important ethical questions that relate not just to doing research ethically for the sake of participants' rights, but to doing better quality research. Particularly, we need to query of ourselves:

- What are our motivations and intentions for investigating this social reality?

- What are the impacts of our interests, biases, preconceptions or intentions on this investigation?

- How do we maintain our values, intentions and commitments throughout the inquiry?

- Within the intended research focus, do the processes of Making Data empower respondents to construct their lived experience in a way and with a focus that is significant to them?

\section{The intentionality of our sense-making (Nicki and Jo)}

This research project began with an interest and the kernel of a rough idea. In our own practice as engineering educators, Jo and I had been struggling with the National Academy of Engineering's (NAE) ${ }^{38}$ Changing the Conversation report on a number of different fronts. On the one hand, we found the NAE's vision to be a compelling one. Yes, we wholeheartedly agreed that engineers could make a world of difference. That math and science did not define engineering. That engineers, at least some of the time, are creative problem solvers. And that, well perhaps in the right context, a career in engineering could be "emotionally satisfying". On the other hand, we felt deeply uncomfortable with the marketing bent of the report, of the ethics of coercing students into engineering with what, we felt, was an incomplete picture of the field. While we believed (and still do) that engineering is key to shaping a better future, we also recognized the field's close ties to the military, it's role in contributing to climate change, and the relationship between engineered products and the unsustainable use of natural resources. Where were these aspects of engineering reflected in the NAE's vision? And, perhaps even more of a concern for us, where was the NAE's vision reflected in the day-to-day practice of undergraduate engineering programs and the career opportunities we pointed our students to? Was it ethical for us to convince our students who were having doubts about if engineering was right for them, many of whom were women, to stay in the field? In short, how did the NAE's "feel good" messages about engineering measure up against the reality of math and science-heavy curricula and the "real-world" of jobs that were on offer?

These were big questions with complex answers. And, for quite some time, we didn't really know how to approach them. It was around this time that I found myself occasionally reading ASEE's First Bell newsletters, particularly articles that described efforts to attract more women to engineering. It was while reading these articles that I noticed the quite striking absence of the NAE's messages. An emotionally satisfying calling? No, engineering was a way to earn a salary on par with men. Make a difference? To the nation's GDP, perhaps, but stories about helping people and improving the environment were rare. And then there were the, what felt like almost daily, articles about robots. Seriously? Robots were going to get more girls interested in engineering?! 
It was at this point that Jo and I sat down and discussed the possibility of using the First Bell news articles as data. What if we could empirically determine the messages that are actually communicated to the public through the mass media about engineering? Could these messages help us to better understand why engineering has such a tough time attracting and retaining women and other underrepresented groups? Might these messages shed some light on the obstacles the NAE would have to overcome for their positive vision to gain real traction? We put together the following three research questions to guide an initial exploration of one year of First Bell news articles:

1. How is engineering portrayed in the media?

2. What explanations are given for a lack of student interest in engineering?

3. What initiatives are reported on to address the lack of interest in engineering?

To assist with the data analysis, we enlisted the help of an undergraduate research assistant, Jennifer. Under Jo's and my guidance, Jennifer would be responsible for sifting through the raw data. Based on our, at this stage fairly superficial, knowledge of First Bell and our backgrounds in engineering education research, Jo and I had a sense of what we thought Jennifer might find in the data. Specifically, we suspected that the majority of articles she'd read would present engineering as being all about "math and science" and the "techy stuff". It therefore came as somewhat of a surprise when Jennifer's first codes focused almost exclusively on the role that engineering and other STEM-related fields play in making the United States' economy globally competitive. And then there were the stories, though relatively much fewer than the ones about how a "chronic shortage of engineers threatens America's economic competitiveness", that reported on the many engineering and STEM graduates who were, in fact, unable to get a job. These articles resonated the most with Jennifer who, at the time, was in her senior year and, like most of her peers, having difficulties finding employment.

As the weekly meetings went on, Jo and I found ourselves having to expand our understandings of what we thought Jennifer would find in the data set. To help with and systemize this process, we asked Jennifer to bring her coding structure and several sheets of printed out example quotes to each meeting. Then, using different colored dry-erase pens and magnets, we would all try to make sense of emerging themes and relationships on a whiteboard. It was in the context of these meetings that we began to notice the presence of several what appeared to be conflicting messages, or "stories" about engineering in the data. As I described earlier, one of these was the contrast between the overwhelming story of there being a "chronic shortage of engineers" versus reports of the apparently increasing numbers of unemployed STEM graduates. Another emergent theme was the ever-present link between the need to excel at math and science in order to be a successful engineer versus the comparatively much smaller number of articles that spoke of engineering as a creative profession. "Right", Jo and I thought, this doesn't sound too dissimilar from the NAE's work on changing the conversation. And so began our efforts to fit the data into two overarching stories: "Materialistic Competitiveness" (our dominant story) and "Holistic Innovations" (the non-dominant counterpart). Jo and I were very excited with this step of the interpretation. Jennifer however, as it turned out, was less so.

Over the coming weeks, Jennifer patiently informed us that innovation is discussed only in the context of how a more diverse workforce leads to more innovation and, therefore, more 
economic growth. There was nothing in the data about "holistic" innovations. And certainly nothing about creativity being used to "make a difference in people's lives". Instead, creativity was the precursor to innovation which, in turn, led to economic growth. Jo and I were not put off so easily. Sure, we could see that most of the articles would speak to the dominant story, Jennifer's early coding trees showed us that. But we wanted her to find evidence of the nondominant story. Not a great pile of it, but at least enough to suggest that the underlying logic was sound. After all, we knew that the world needed creative engineering solutions to "make a difference in people's lives", surely this would be reflected in at least some of the data.

At the same time, we also started having difficulties with the dominant story as Jennifer began to show us different facets of this story, some of which seemed to be in conflict with each other, and most of which were terribly oversimplified in the "Materialistic Competitiveness" narrative as it stood at that point in our model development. With almost all of the data falling in the general direction of the "Materialistic Competitiveness" story line, our model lost its clarity and purpose. The frustration at these meetings was palpable.

Months later, after several other attempts to make sense of and model the data, we eventually arrived at an interpretation that captured both the complexity and coherence of the news articles and, at the same time, cast a different light on the challenge of diversifying engineering ${ }^{4}$. That was a much happier day than the weeks of frustration when we felt we might be trying to "force fit" the data into a flawed model.

The contribution of this shared process of co-construction to the quality of the research can be dispassionately understood through the lenses of Procedural and Theoretical Validation. Specifically, Jo and I purposefully designed the weekly meetings as a mechanism through which the entire research team could work toward improving the fit between the reality studied and the theory generated while staying firmly grounded in the data. Our specific procedures included team discussions around Jennifer's coding trees, working on the whiteboard with printed out quotes from the data, and the iterative development of an illustrative model that we updated each week in Microsoft Visio. In our later discussions with Alice, however, Jo and I realized that describing the meetings in terms of Procedural and Theoretical Validation was missing an important part of the picture, specifically, the part concerned with Jo and I walking that fine line between, on the one hand, using our prior understandings of engineering education to orient the study and give us a head start on the interpretation and, on the other, recognizing when our hunches or preconceptions became interpretive obstacles that, in effect, blinded us from seeing the empirical reality that was before us.

But there was still more than that. Even though Jo and I both studied engineering, our current research mostly entails the use of qualitative methods to answer educational/ engineering practice questions. For different reasons, we both decided not to pursue what might be considered as traditional careers in engineering practice. Not surprisingly, our personal experiences of studying and working in the field did find their way into the interpretive discussions. Our efforts to stay close to the data through the explicit use of Theoretical and Procedural Validation strategies went some way toward tempering these influences. At the same time though, as we later discussed in the context of our monthly discussions with Alice, these perspectives were also valuable. 
For example, the very idea and impetus for the study was in part motivated by our perception of a need for the research and a sense of the potential to contribute an evidence-based, but perhaps different theoretical perspective to the discussion around engineering student recruitment and diversity. In the data analysis steps described above, those influences manifested as an intentional and directed process of sense-making. Understanding our work as interpretive, we did not assume findings to 'emerge' in a value-free manner from a neutral, and presumably undirected, interaction of the researcher with the data. Rather our efforts to understand the social world were always intentional $^{39,40}$, not in the sense of superimposing an ill-fitting interpretation on a social reality, but in the sense of being directed towards an outcome, whose nature and shape we iteratively negotiated between our assumptions and a growing knowledge of the context we are interested in. Purposefully utilizing our human intentions in the research and balancing those with a trustworthy process grounded in the data, thus became a quality as well as an ethical consideration.

More specifically our intentions and values made it difficult for us to "let go" of some of our assumptions, thus making it critically important to the success of the project that we acknowledge the potential and varied impacts own interests, biases, or intentions might have on the project. To qualitative researchers, this is not an earth shattering revelation. One of the first tasks novice qualitative researchers are asked to engage in is to write a subjectivity statement. What we experienced in this project, however, was more than that. Rather than something to be acknowledged and written about at the outset of a project, we experienced considerations of our prior experiences to be crucial to ensuring the quality of the findings throughout the entire research process - from deciding which research question to investigate, to selecting and interpreting data, persevering through difficult patches, all the way through to the commitment to engage with relevant audiences and broadly disseminate the study findings. We propose that the notion of Ethical Validation has the potential to capture the "entire process" nature of these considerations. Specifically, we see a need to ask ourselves:

- How can we balance the productive intentionality of our processes of sense-making (e.g. hunches, motivation) against the risk of mis-constructing the social reality under investigation?

\section{The challenge of capturing all facets of the richness in our participants' accounts (Alice)}

I return to Moises's interview to discuss an additional issue we relate to ethical validity. Upon returning home, I had the interview transcribed, and we sent it past Moises as per our protocol. When we sat down to analyze it, however, I found we were stuck. My plan had been to do a thematic analysis, as I had done for other studies. But when we tried to code Moises's interview, I felt the emotion and power of his story drain away. It was like Moises had had no need for tissues, hadn't expressed such fear and pain to a stranger. It felt like a dishonest representation of his story.

Returning to the Quality Framework didn't really help me out of my predicament this time. I felt resonance with questions embedded in Communicative Validation - for example, I felt it important to reflect on how I was co-constructing Moises's story through our analysis and 
therefore had a responsibility to represent his social reality throughout the analysis - but there seemed to be something still missing. In my conversations with Jo and Nicki, I found myself asking slightly different questions, ones about "justice" of which I was again poorly equipped to make sense of. While there was plenty of research literature that would justify my systematic coding of Moises's story and the findings that came from this activity, there was little to help me justify searching for a different analytical choice based on this sense that the planned method would be "doing wrong" to the participant.

But by listening to my sense of disquiet with the analysis plan, I found I needed to approach these data with a way to preserve the emotion and drama that I had felt in their telling - we needed a way for the data to stay stories rather than be chopped up into disconnected chunks and filed by theme. As a result, we have decided to explore narrative analysis which prioritizes the way in which the participant tells the story themselves, rather than breaking it up to fit the priorities of the research team. Because we ourselves lacked skills in this area, we have started to reach out more explicitly to colleagues to explore it in community, generating valuable research collaborations across areas. We have started to write about our experience doing this (Pawley 2013, 2014), feeling like we are making ourselves and our work more vulnerable but finding colleagues very receptive to the conversation. Through these efforts, generated by this initial sense of discomfort, we feel we have been able to strengthen our work's Communicative Validation and Procedural Validation as well ${ }^{28}$. But the generating prompt was the sense of something "not right" in our plan when applied to our collected data. In our shared explorations, we captured this emerging facet of ethical validation in the question:

- Do our analytic processes and our interpretations appropriately and responsibly account for the emotional richness of our participants' accounts?

\section{Interpretive data analysis as a shared endeavor (Nicki and Jo)}

Jennifer was a sophomore student when she started working with us with no prior experience in or exposure to qualitative research. For the first few months, Jennifer and I met so I could teach her how to code using the constant comparative method ${ }^{41,42}$ and how to use NVivo, the qualitative analysis software we had chosen for the project.

I had taught Jennifer in her freshman year and so we had a pre-existing instructor-student relationship. Later in the project when Jennifer was a junior, she took another one of my classes in environmental engineering. In light of the quite different nature of the research project as compared to engineering coursework, I tried to set Jennifer specific, manageable weekly tasks. As she progressed and became increasingly comfortable with her coding abilities, I gradually sought to treat her less as "a student" and more as an equal member of the research team. Given Jennifer's close engagement with the raw data, it was crucial to the success of the project that she felt confident enough to speak up during the weekly meetings.

As I described in the second anecdote above, as it turned out Jennifer did speak up at meetings. She had no fear telling Jo or I when she thought we were off the mark. In fact, sometimes Jo and I wondered whether we would ever be on the mark, in Jennifer's eyes; or rather, in the eyes of the data she was so deeply engaged in. Even though some of these meetings were difficult, Jo 
and I repeatedly reminded Jennifer (and ourselves) that such difficulties were part and parcel of the process of Communicative Validation. Together, Jennifer Jo and I constituted a "communication community"1,13 responsible for the co-construction of meaning from the data. By allowing and even encouraging each other to disagree and ask questions, our interpretations were more likely to evolve to such a point where they both "fit" with the social reality under investigation and contributed a novel insight to the engineering education community. In another publication, Jo and I have discussed this meeting dynamic as "productive interpretive dissonance," 28 .

In our conversations with Alice, however, we couldn't help but feel that Communicative Validation did not altogether capture the human quality of the interactions that occurred during this phase of the project. For example, in addition to simply hiring Jennifer as an undergraduate research assistant to help out with our project, I also felt a deep sense of responsibility for her professional development. I didn't want her to do "busy-work", or at least not all of the time. I wanted to show her the depth and explanatory power of qualitative research. At the same time, I wanted for her to walk away with something, not just clocked up hours and a paycheck, but a feeling of having been part of something and of ownership over the product (of course part of me also wished that she would stay on after graduation, unfortunately that didn't happen). These feelings extended far beyond the notion of Communicative Validation and, perhaps, also factored into my own frustrations when I felt that we weren't getting anywhere with our interpretations. What would she have walked away with then?

As we discussed above in the literature review, feminists have called into question the power relationships that characterize traditional, 'objective' research. Normally, however, these relationships refer to interactions between the researcher and the researched. In this case, the power relationships that Jo and I wanted to reconsider were between members of the research team, the 'experts' and the 'non-expert', the instructors and the student. Interestingly, as I point out above, this decision was as much motivated by a sense of responsibility as a commitment to research quality. Similar to Alice's first anecdote, and also Mia Ong's decision to get "involved" with her participants ${ }^{11}$, what Jo and I thought was the "right" thing to do also coincided with the "right" thing for our project. In our conversations with Alice, we came to understand this aspect of the project as another example of Ethical Validation underpinning, connecting to, and contextualizing the other quality considerations. More specifically, our discussions on this topic led us to formulate the following question:

- How can we meaningfully and equitably engage all members of the research team?

\section{The impacts of our research and its findings (Alice)}

Returning to the Learning from Small Numbers (LfSN) study, I have written about how the emotional experience of doing the interviews caused us to shift our analytical plan. However, it also had ramifications for how we talk about this study with others in our "communication community," as per the Quality Framework. 
After the interview, I felt a great responsibility not only to analyze this story justly, but also I felt a responsibility to make that story do as much work as it possibly could. This meant also sharing it with as many relevant listeners as possible.

I felt - and still feel - a great quandary. I had started to reflect how my own white privilege was influencing the study motivation and design, the data collection, and the analysis. But what did I imagine as the end? Was I trying to act as White knight, seeking to (problematically) "rescue" underrepresented communities from the continuing oppression of what bell hooks has called the "imperialist white supremacist capitalist patriarchy"

At the same time, I recognize I am part of a large body of researchers trying to crack why engineering education remains so exclusive, and it is the subjects of this issue who have to keep telling their stories over and over and over to yet more researchers trying to figure things out. How, this time, then, would I make the data do as much work as it could on behalf of the students?

I started to reflect about the different communities that needed to learn from the stories of the study's participants. I and others had published our work in peer-reviewed conferences and archival journals; but did the people who made these decisions day-to-day actually read those papers? Probably not. So I have needed to reconsider how to make these data and these analyses do as much work on the system itself as they possibly can, not just the research world, but in the practice world of engineering education. This means reaching out to deans, department heads, curriculum chairs, even perhaps instructors where they are, and using the tools that they use to make their heretofore inarticulable ruling relations manifest in the structure of university engineering education. In other words, we need to consider what are appropriate theories of how the folks in the trenches of social reproduction do their work, and then design learning opportunities that will really "move the needle." Furthermore, we needed to consider this during the process of analysis to help keep our eye on the ball of what change we wanted to prompt. If we didn't, we risked producing products that the actors we wanted to influence still would not effectively use.

There was a second issue I was wrestling with also. Since the study design's start, I had been resisting the idea that I should send analysis past participants for their discussion - what others had done as a "member check" to increase the trustworthiness of qualitative analyses ${ }^{44-46}$. I had resisted this for two reasons. First, I did not want to impose on participants for even longer than I already had, in recognition of the fact that they may have been asked to tell their story many times over, and by virtue of their gender and/or race, would likely be asked again. Second, I wanted to recognize the criticism I had read from participants of other studies - that just because a participant was a woman, for example, didn't mean that she was particularly interested in issues of gender in her research sphere. In conversation with Jo and Nicki, I learned about the "experience distant construct"14 and thought this provided justification for my choice to leave participants out of the cycle of research-to-practice.

In conversations with colleagues, I realized I had a different lens on racial oppression - while I experience White privilege daily, I had also had the opportunity to learn about race theory in a way that some of my colleagues of color had not. While I could never come to fully understand 
their experience of race in STEM, I had a theoretical language that sometimes seemed to help them make sense of that experience. Who was I to deny participants this same opportunity - to learn, as Mia Ong put it, to gain "a more sophisticated vocabulary, discourse, and frame of analysis to understand and talk about their own experiences" ${ }^{\prime 1}$ ?

This was a different outcome than I had been considering. I had been striving to do research that did not "blame the victims" for their own circumstances and as a result had been blind to the idea that participants themselves could benefit directly from the research. Through my reflection, I have come to think that participants have the right to read our work, should be invited to read our work on their stories, that this is another form of a "just" outcome from this research that will also help improve its quality, through, for example, continuing to develop a relationship with participants ${ }^{11}$.

Here again do we find the utility of the "ethical validation" concept. Late in the process, I had stumbled across these concepts in conversations with Jo and Nicki and in following our analyses. But a systematic treatment of these earlier in the course of the study would have been possible had we had the right lens to use - in other words, I have come to think that the process by which we stumbled, as it were, is not necessary to being able to have the revelation in the first place. These two stories taken together yield the final queries suggested in our Ethical Validation concept we propose here:

- Do the ways in which we generate and disseminate our findings and their ultimate use do justice to the participants' lived experiences and their commitment to sharing them with us?

- What are the impacts of our research for the social reality investigated and for similar social realities?

\section{Discussion}

The above collaborative inquiry revealed how ethical and quality considerations were connected in the context of two example projects. More specifically, we identified a number of significant research challenges and collectively explored these through the prior research Quality Framework, which provided precise insight into the theoretical, methodological nature of the issues encountered in practice. However, underlying each of the quality challenges we found a layer of the profoundly human experience of conducting interpretive research that was not captured in our theoretical explorations and is not commonly acknowledged in discussions of methodology. More specifically, a range of deep ethical considerations and the aspect of both researchers' and participants' emotions in the process seemed to fundamentally underpin the quality considerations but were not reflected in the theoretical examinations using the existing five categories. Through shared discussions we began to understand our research projects as shared encounters between researcher and 'researched' and within the research team. In the context of each anecdote, we have captured facets of this human element in the specific probing questions out of which emerged the coherent notion of Ethical Validation we present here. The questions in Figure 1 that trace Ethical Validation throughout the process of inquiry are not intended to be comprehensively definitional nor prescriptive for Ethical Validation but are framed broadly as to be transferable to other research contexts. 


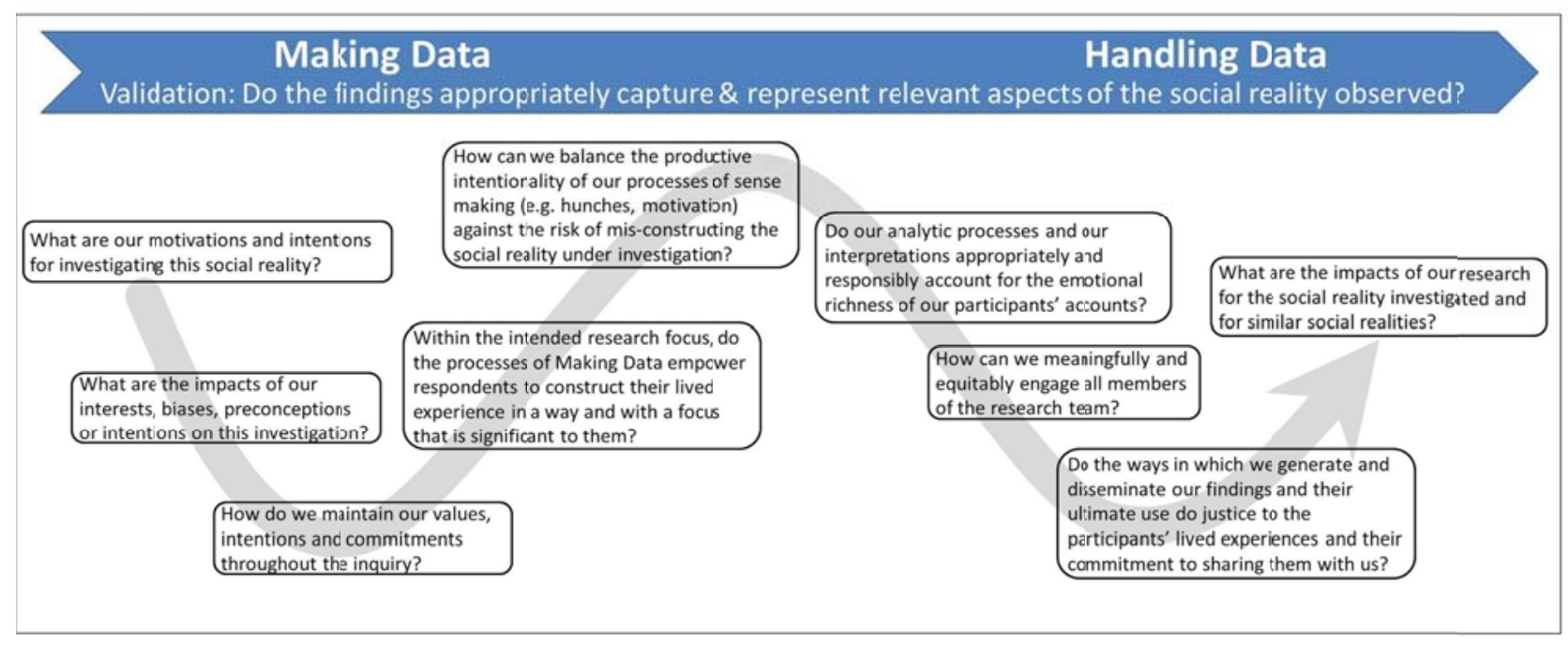

Figure 1: Model of Ethical Validation

Figure 1 illustrates how the notion of Ethical Validation spans the entire research process from early conceptual phases to the ultimate impact of research findings, thus complementing the research Quality Framework that theoretically guided our collaborative inquiry. More specifically, Ethical Validation complements and productively intersects with the existing quality dimensions as illustrated in each anecdote. We propose that the overall research Quality Framework with the added dimension of Ethical Validation captures the theoretical, methodological, as well as ethical dimensions of research quality and explores their inherent connections. This approach thus offers a concrete, practice-based way to integrate prior programmatic explorations of the connection between ethical aspects and research quality into engineering education research practice across a range of interpretive methodologies. The following summarizes the key insights we propose should guide such implementation efforts or further conceptual explorations.

1. Ethical considerations should be integrated throughout the entire research process with continuous critical attention to the profoundly human elements that are not captured in the conventional considerations of ethics that emphasize research planning and are grounded in the pragmatic notion of value-free social research that views ethical considerations as external to the research process.

2. Through this attention to the human element underlying interpretive research, we propose to extend our conception of a non-dualistic ontology as bias and mutual influence between researcher and researched to conceptualize research as entering a community with our respondents, our co-researchers, and ultimately with the 'customers' of our research outcomes.

3. Our shared exploration presented here offers some first glimpses on such a holistic conception of research as community which powerfully illustrates that ethical considerations in interpretive research are not separate from but rather underlie and are inherent to overall research quality. 


\section{Acknowledgements}

This material is based upon work supported by the National Science Foundation under Grant No.s 1055900 and 1150668. Alice wishes to thank the students who have participated in her study for sharing their stories, and the Feminist Research in Engineering Education (FREE) research group, particularly Canek Phillips who works on the LfSN project. Nicki and Jo wish to thank their undergraduate research assistant, Jennifer Wilson, for her valuable feedback on the second and fourth anecdotes in this paper.

\section{References}

1. Walther, J., N.W. Sochacka, and N.N. Kellam, Quality in Interpretive Engineering Education Research: Reflections on an Example Study. Journal of Engineering Education, 2013. 102(4): p. 626-659.

2. Pawley, A.L., Learning from small numbers of underrepresented students' stories: Discussing a method to learn about institutional structure through narrative. 2013.

3. Pawley, A.L. and M.L. Phillips Canek, From the mouths of students: Two cases of narrative analysis to understand engineering education's ruling relations as gendered and raced. 2014.

4. Sochacka, N.W., et al., Stories 'Told' about Engineering in the Media: Implications for attracting diverse groups to the profession, in Frontiers in Education2014: Madrid, Spain.

5. Hammersley, M. and A. Traianou, Ethics in Qualitative Research: Controversies and Contexts. 2012: SAGE Publications.

6. $\quad$ Miller, T., et al., Ethics in Qualitative Research. 2012: SAGE Publications.

7. United States National Commission for the Protection of Human Subjects of Biomedical Behavioral Research, Belmont report - ethical principles and guidelines for the protection of human subjects of research. 1974.

8. Christians, C.G., Ethics and Politics in Qualitative Research, in The SAGE Handbook of Qualitative Research, N.K. Denzin and Y.S. Lincoln, Editors. 2011, SAGE Publications.

9. Haraway, D., Situated Knowledges: The Science Question in Feminism and the Privilege of the Partial Perspective. Feminist Studies, 1988. 14(3): p. 575-599.

10. Harding, S., Whose Science? Whose Knowledge?: Thinking from Women's Lives. 1991, Ithaca, NY: Cornell University Press.

11. Ong, M., Achieving Multi-Sitedness and Social Justice: “Methodological Activism” and Other Dilemmas in Physics Education Research, in American Educational Research Association2005: Montreal, QC.

12. Tuhiwai Smith, L., Decolonizing Methodologies: Research and Indigenous Peoples. 1999, New York: Zed Books.

13. Apel, K.O., The a priori of communication and the foundation of the humanities. Man and World, 1972. 5(1): p. 3-37.

14. Geertz, C., From the Native's Point of View: On the Nature of Anthropological Understanding. Bulletin of the American Academy of Arts and Sciences, 1974. 28(1): p. 26-45.

15. Bray, J.N., Collaborative Inquiry in Practice: Action, Reflection, and Making Meaning. 2000: SAGE Publications.

16. Heron, J. and P. Reason, A Participatory Inquiry Paradigm. Qualitative Inquiry, 1997. 3: p. 274-294.

17. Kasl, E. and L. Yorks, Collaborative Inquiry for Adult Learning. New Directions for Adult \& Continuing Education, 2002. 2002(94): p. 3.

18. Love, N., Using Data to Improve Learning for All: A Collaborative Inquiry Approach. 2008: SAGE Publications.

19. Reason, P. and H. Bradbury, The SAGE Handbook of Action Research: Participative Inquiry and Practice. 2007: SAGE Publications.

20. Yorks, L. and E. Kasl, Learning from the Inquiries: Lessons for Using Collaborative Inquiry as an Adult Learning Strategy. New Directions for Adult \& Continuing Education, 2002. 2002: p. 93.

21. Mezirow, J., Transformative dimensions of adult learning. 1991: ERIC.

22. deMarrais, K.B., Inside Stories: Qualitative Research Reflections. 2012: Taylor \& Francis. 
23. Smeyers, P., Idle research, futile theory, and the risk for education: Reminders of irony and commitment. Educational Theory, 2005. 55: p. 164-183.

24. Walther, J., N.W. Sochacka, and N.N. Kellam. Longitudinal workshop 1 - Exploring the Quality Framework. in Qualifying Qualitative Research Quality (Q3): . 2013. Athens, GA.

25. Smith, D.E., The everyday world as problematic: a feminist sociology. Northeastern series in feminist theory, ed. E.F. Keller. 1987, Boston, MA: Northeastern University Press.

26. Smith, D.E., Texts, facts and femininity: exploring the relations of ruling. 1990, London: Routledge.

27. Smith, D.E., Institutional ethnography: a sociology for people. Gender Lens. 2005, Lanham, MD: Altamira Press.

28. Walther, J., et al., Qualitative Research Quality: Practice explorations from multiple methodological perspectives. Journal of Engineering Education, in preparation.

29. Slaton, A.E. and L. Pawley Alice, The Power and Politics of STEM Research Design: Saving the "Small $N$ ”, in American Society for Engineering Education Annual Conference \& Expositionin preparation: Seattle, WA.

30. Entman, R.M., Framing: Toward clarification of a fractured paradigm. Journal of Communication, 1993. 43(4): p. 51-58.

31. Roe, E.M., Narrative Policy Analysis: Theory and Practice. 1994, Durham, NC: Duke University Press.

32. Brewer, M., N.W. Sochacka, and J. Walther, Into the Pipeline: A freshman student's experiences of stories 'told' about engineering in American Society for Engineering Education Annual Conference \& Expositionin preparation: Seattle, WA.

33. Hoegh, J. and A.L. Pawley, Modeling the career pathways of women STEM faculty through oral histories and participatory research methods. 2010.

34. Jones, K.E., et al., Examining the flexibility bind in American tenure and promotion processes: An institutional ethnographic approach. Ethnography and Education, 2014. 9(3): p. 328-342.

35. Schimpf, C., A.L. Pawley, and M.M. Santiago, Access and definition: Exploring how STEM faculty, department heads and university policy administrators navigate the implementation of a parental leave policy, in American Society for Engineering Education Annual Conference2012: San Antonio, TX.

36. Schimpf, C., et al., STEM faculty and parental leave: Understanding the challenges through structuration theory. International Journal of Gender, Science, and Technology, 2013. 5(3): p. 103-125.

37. Crenshaw, K., Demarginalizing the intersection of race and sex: A Black feminist critique of antidiscrimination doctrine, feminist theory and antiracist politics. The University of Chicago Legal Forum, 1989: p. 139--168.

38. National Academy of Engineering, Changing the Conversation: Messages for Improving Public Understanding of Engineering. 2008, Washington D. C.: The National Academies Press.

39. Husserl, E., Logische Untersuchungen zweiter Teil: Untersuchungen zur Phänomenologie und Theorie der Erkenntnis. 1901, Halle a.S.: Max Niemeyer.

40. Husserl, E., Cartesian meditations: an introduction to phenomenology. 1960, The Hague: Nijhoff. 157.

41. Glaser, B.G., The constant Comparative Method of Qualitative Research, in Issues in participant observation: a text and reader, G.J. McCall and J.L. Simmons, Editors. 1969, Addison-Wesley Pub. Co: Reading, MA. p. 216-228.

42. Hatch, J.A., Doing qualitative research in education settings. 2002, Albany, NY: State University of New York Press. 299.

43. hooks, b., Understanding patriarchy, in http://imaginenoborders.org/pdf/zines/UnderstandingPatriarchy.pdf, N. Borders, Editor; not dated.

44. Carlson, J.A., Avoiding Traps in Member Checking. The Qualitative Report, 2010. 15(5): p. 1102-1113.

45. Creswell, J.W. and D.L. Miller, Determining Validity in Qualitative Inquiry. Theory into Practice, 2010. 39(3): p. 124-130.

46. Sandelowski, M., Rigor or rigor mortis: The problem of rigor in qualitative research revisited. Advances in Nursing Science, 1993. 16(2): p. 1-8. 